\title{
Women Obscenity in India: Social Outlook with Legal Reflection
}

\section{Sanjoy R*}

Associate Professor, Department of Social Work, University of Delhi, India

*Corresponding author: Dr Sanjoy Roy, Associate Professor, Department of Social Work, University of Delhi, India, Tel: 9971352017; Email: sanjoyroy30@gmail.com

\section{Review Article \\ Volume 4 Issue 2}

Received Date: February 12, 2020

Published Date: March 04, 2020

DOI: $10.23880 /$ jenr- 16000190

\section{Abstract}

The term 'obscenity' is most often used in a legal context to describe expressions in terms of words, images, actions etc. but it has also linked with sexual morality of the time or otherwise taboos. Obscenity includes pornography but may also include nude dancing, sexually oriented commercial telephone messages etc. In the era of social media/internet, obscenity has increased extremely than ever. The internet user base in India has exceeded 627 million by end of 2019 in India and Internet content is completely unregulated, there is no law or regulation that requires censorship of films and shows that are streamed online on the online video streaming platforms like Netflix, Amazon Prime, Hot star etc. Though, the Supreme Court recently had issued a notice to Centre in response to a petition which was filed for seeking guidelines in order to regulate the unregulated, uncertified, pornographic, obscene, sexually explicit, vulgar and profane content on these platforms.

Therefore, the question is how you would determine obscene and sexually explicit content and to control \& regulate it. In this regards the need of the hour is to generate a climate for public dialogue and discussion. Also a mechanism should be developed to ensure viewer's feedback, not only on performance but also on expectations, reservations and objections of it. Even the media/social media should play equal responsibilities with parents in creating circumstances and viable conditions that enable projection of women in a decent, dignified way and promote violence free programmes and in general, may be used for provoking thoughts on sensitive issues like sexual harassment, violence against women, denial of opportunities to girl children, reducing manliness among males by showing the relationship between aggressive behaviour and risk taking behavior among men.

In this article the discussions have been bounded around the real issues of women obscenity and its legal parameters and implications from societal perspective in India.

Keywords: Obscenity; Pornography; Electronic Media; Information Technology Act, 2000; Indian Court

\section{Introduction}

An obscenity in Latin Obspenus, meaning 'foul, repulsive, detestable' is that which offends the prevalent sexual morality of the time, is a profanity, or is otherwise taboos, indecent, abhorrent, or disgusting, or is especially inauspicious; illomened. The term obscenity is most often used in a legal context to describe expressions in terms of words, images, actions etc. The word can be used in such uses as "obscene profits", "the obscenity of war", etc. It is often replaced by the word salaciousness. According to Merriam-Webster online dictionary, that which is obscene (i.e.: an obscenity) is quite simply defined as repulsive, or disgusting to the senses. The definition of what exactly constitutes an obscenity differs from culture to culture, between communities within a single culture, and also between individuals within those communities. Obscenity is a legal term that applies to anything offensive to morals and is often equated with the term pornography. Pornography, however, is a more limited term, which refers to the erotic content of books, magazines, films, and recordings. Obscenity includes pornography but may also include nude dancing, sexually oriented commercial telephone messages, and scatological comedy routines. 


\section{Journal of Ecology and Natural Resources}

The internet user base in India has exceeded 627 million by end of 2019. In India, Internet content is completely unregulated, there is no law or regulation that requires censorship of films and shows that are streamed online on the online video streaming platforms like Netflix, Amazon Prime, Hotstar etc. The talks to regulate this content are catching heat in India. A petition filed by an NGO, Justice for Rights Foundation in Hon'ble Delhi High Court was dismissed. The division bench of Delhi High Court while dismissing the petition said that they cannot frame any guidelines in this matter or pass any other order, because there are stringent provisions already in place under the Information and Technology Act (https://www.outlookindia. $\mathrm{com} /$ newsscroll/kantar-imrb-releases-the-twentyfirstedition-of-icube-report/1491589). However, this same NGO has again filed a petition in Humble Supreme Court of India seeking framing of guidelines for the content on online video streaming platforms like Netflix, Amazon Prime Video, Hotstar. The Supreme Court has issued notice to Centre in response to this petition. This petition is filed for seeking guidelines in order to regulate the unregulated, uncertified, pornographic, obscene, sexually explicit, vulgar and profane content on these platforms. The question is how you would determine obscene and sexually explicit content.

In this article the discussions have been surrounded around the real issues of women obscenity and its legal parameters and implications from societal perspective in India.

Indian Constitution enshrines equal status to women by conferring upon them right to equality under Article 14 . This right is further improved upon by conferring special provisions under Article 15 (3) of the Constitution by providing reservations to women in matters of employment and education. In 1992, the Constitution was amended to reserve 33 percent of the seats in favour of women in panchayats and municipalities. These legal provisions are regarded as a major footstep for the socio-economic empowerment of women in India. Yet, the status of equality has been still a myth to millions of women. Even today, they are victims of various forms of violence or harassment within houses, in the educational field and at work places as well. Further, with the advent of technology and scientific up gradation, the victimization of women has increased posing a major threat to the security of their person as a whole in the form of cybercrimes. We are now in the midst of a third major revolution in human civilization i.e. information revolution after agricultural revolution, and industrial revolution.

\section{The Definition of Obscenity given by Supreme Court as follows}

1) A thing must be prurient in nature
2) A thing must be completely devoid of scientific, political, educational, or social value

3) A thing must violate the local community standards

If it meets all three of these things, it is obscenity.

\section{Analysis of Obscene and Obscenity}

The concept of obscenity is related to morality in our society and it promotes the violation of the law and the general corruption of morals. The exhibition of an obscene picture is an unlawful offence at common law, although not charged to have been exhibited in public, if it be avowed that the picture was showed to sundry persons for money. For something to be "obscene" it must be shown that the average person, applying contemporary community standards and viewing the material as a whole, would find [1] that the work appeals predominantly to "prurient" interest; [2] that it depicts or describes sexual conduct in a patently offensive way; and [3] that it lacks serious literary, artistic, political or scientific value.

An appeal to "prurient" interest is an appeal to a morbid, degrading and unhealthy interest in sex, as distinguished from a mere candid interest in sex. The first test to be applied, therefore, in determining whether given material is obscene, is whether the main theme or purpose of the material, when viewed as a whole and not part by part, and when considered in relation to the intended and probable recipients, is an appeal to the prurient interest of the average person of the community as a whole, or the prurient interest of members of a deviant sexual group, as the case might be. The "predominant theme or purpose of the material, when viewed as a whole," means the main or principal thrust of the material when assessed in its entirety and on the basis of its total effect, and not on the basis of incidental themes or isolated passages or sequences. Whether the predominant theme or purpose of the material is an appeal to the unhealthy interest of the "average person of the community as a whole" is a judgment which must be made in the light of contemporary standards as would be applied by the average person with an average and normal attitude toward, and interest in, sex. Contemporary community standards, in turn, are set by what is accepted in the community as a whole; that is to say, by society at large or people in general. So, obscenity is not a matter of individual taste and the question, is not how the material excites an individual juror; rather, as stated before, the test is how the average person of the community as a whole would view the material. In addition to considering the average or normal person, the unhealthy appeal requirement may also be assessed in terms of the sexual interest of a clearly defined deviant sexual group if the material was intended to appeal to the prurient interest of such a group as, for example, homosexuals. The second test to be applied in determining whether given material 
Journal of Ecology and Natural Resources

is obscene is whether it depicts or describes, in a patently offensive way, sexual conduct such as ultimate sexual acts, normal or perverted, actual or simulated; masturbation; excretory functions; or lewd exhibition of the genitals measured against whether the material is patently offensive by contemporary community standards; that is, whether it so exceeds the generally accepted limits of candor as to be clearly offensive. Contemporary community standards, as stated before, are those established by what is generally accepted in the community as a whole; that is to say, by society at large or people in general, and not by what some groups of persons may believe the community as a whole ought to accept or refuse to accept. It is a matter of common knowledge that customs change and that the community as a whole may from time to time find acceptable that which was formerly unacceptable. The third test to be applied in determining whether given material is obscene is whether the material, taken as a whole, lacks serious literary, artistic, political or scientific value. An item may have serious value in one or more of these areas even though it portrays explicit sexual conduct. All three of these tests must be met before the material in question can be found to be obscene. If any one of them is not met the material would not be obscene within the meaning of the law. Therefore, 'Obscenity 'is a difficult term to explain as it is tortuously linked to the moral values our society. The Courts have laid down a principle saying that the test to determine obscenity is whether the tendency of the matter, charged with obscenity is to deprave and corrupt those whose minds are open to such immoral influences and into whose hands a publication of this sort may fall. If it does, the matter falls within the purview of obscenity.

Section-292-294 of the Indian Penal Code, 1860 deals with the sale, hire, distribution, public exhibition, circulation, import, export or advertisement etc. of anything obscene. For sale etc. of obscene books, the punishment is imprisonment up to 2 years and fine up to Rs.2000 on first conviction and imprisonment up to 5 years and fine up to Rs. 5000 on subsequent convictions. For sale etc. of obscene objects to young person under the age of 20 years, punishment is imprisonment up to 3 years and fine up to Rs. 2000 on first conviction and imprisonment up to 7 years and fine up to Rs. 5000 on subsequent convictions. Anybody who does any obscene act in public places or sings, recites or utters any obscene songs in or near any public places is punishable with imprisonment up to 3 months or with fine or both.

But exceptions are there: Any book, pamphlet, paper, writing, drawing, painting, representation or figure which is published in the interest of science, literature, art or learning or in general concern or which is kept or used bona fide for religious purposes; any representation sculptured, engraved, painted or otherwise represented on or in any ancient monument or temple or conveyance of idols, it will not be obscenity.

\section{Law relating to electronic media and cyber obscenity}

In India, there are few laws/acts which can somehow control these kinds of obscenity. The Cable Television Network regulation Act, 1995, prohibits the telecast of obscene content on television. Further, Sections 4 and 5A of Cinematographs Act, 1952, (The Cinematographs (Amendment) Bill, 2019) provides that the films should be examined before release. The Cable Television Network Act clearly mentions that 24 hours NO ADULT programme can be shown on television [4].

India enacted its Information Technology Act in 2000 and thereafter amended the said Act in 2008 to combat cybercrimes. However, issues relating to online sexual abuse of women still remain untouched under the said Act. Cyber spaces have become havens for cyber criminals. Women are the most vulnerable targets in the internet. They have been victimized more specifically in the social networking websites. Apart from women, there are millions of men and children who are also the victims of cybercrimes. The major types of cybercrimes which are directed against women are harassment via emails, cyber stalking, cyber pornography, obscenity, defamation, morphing and email spoofing. Various factors could be accredited towards online victimization of women. In majority cases, offenders target the victim for sexual purposes. Cyber sexual abuse can even be witnessed in the form of cyber pornography or cyber obscenity. Cyber obscenity includes pornographic websites, pornographic online magazines and the internet to download and transmit pornographic pictures, photos and writing. The photographs of women are used, morphed and distributed in the internet with obscene postures. The offender may even part messages using filthy language. Concerning the law pertaining to the offence of cyber obscenity, S-67 and S-67A of the Information Technology Act, 2000 are the first provisions dealing with obscenity on the internet in India. These sections deal with obscenity in electronic spheres and provide punishment for publishing or transmitting obscene materials in electronic form. Punishment for publishing or transmitting of material containing sexually explicit act etc., in electronic form extends from three to seven years of imprisonment and fine ranging from five to ten lakh rupees. However, it must be noted that the test to determine offence of cyber obscenity as per the Information Technology Act, 2000 has identical ingredients as provided under Section 292 of the Indian Penal Code, 1860. Even the term 'indecency' can be interpreted so as to fall within the preview of the definition of obscenity. Also, the legal understanding of pornography and obscenity has often overlapped with each other. The Code in specific does not lay down any test to determine obscenity. It merely prohibits 
Journal of Ecology and Natural Resources

the sale or distribution or exhibition of obscene words, etc. in public places. Hence, this test would involve investigation of whether the tendency of matter charged as obscene is to deprave and corrupt those whose minds are open to such immoral influences and into whose hands a publication of this sort is likely to fall. This test is similar to the test put forth in the ruling of R. v. Hicklin, 1868, (British Law Case) wherein, the Court held that "a publication or content is obscene if it tends to produce lascivious thoughts and arouses lustful desire in the minds of substantial numbers of that public into whose hands the book is likely to fall. Hence, the freedom of speech and expression are restricted in the interest of decency and morality." However, the Supreme Court is of the opinion that there is no fixed standard to determine what is moral and what is decent. The standard of morality varies from time to time and from place to place. The Courts observation cannot be discarded since birth control which was once considered immoral is now considered moral and a means to control over population. Similarly, kissing or hugging scene in Indian cinema has now come to be tolerated by urban viewers but countryside viewers still do not approve such film scenes (https://www.britannica.com/topic/Regina-v-Hicklin).

The Supreme Court again in the year 2007 while recognizing the right to adult entertainment, reviewed the position of law on obscenity and summarized the test regarding obscenity. As per this test the picture of a woman in nude/semi-nude is not per se obscene unless there is something in it which would offend the taste of an ordinary decent minded person. The court was more referring to the content. In the sense, the content is regarded as obscene only when treatment of sex becomes offensive to public decency and morality, judged by the prevailing standards of morality in the society. The Court did not define pornography, neither did it explain the meaning of sexually explicit content, but from the explanation for understanding the meaning of obscenity, it is clear that not all contents which have some sexual flavor can be regarded as obscene. In this way, the meaning or interpretation of obscenity can be subjective depending on the culture. Even the definition of 'decent minded person' would also differ as per culture. These discussions later on leads to enact the Indecent Representation of Women (Prohibition) Act, 2008 to include such acts of representation of women, which did not fall within the ambit of obscenity. But matters pertaining to cyber obscenity are still not included in the said Act. The Act focuses only on print media. It does not have sufficient powers to deal with the electronic media, the internet and mobile phones. This shows online sexual abuse or harassment is not taken that seriously as other forms of abuses. Till today the legal trend in this sphere has proved to be ineffective in assuring fair justice to women. Even the judiciary has not adequately considered the ways in which woman can be abused and subjected cyber obscenity. Thus, the victimization of women still continues in silence.

\section{Indian Courts on Obscenity}

Indian Judiciary for the first time defined obscenity in the case of Ranjit D. Udeshi v. The State of Maharashtra. In this case Hon'ble Supreme Court observed that the test of obscenity is, whether the tendency of the matter charged as obscene is to deprave and corrupt those whose minds are open to immoral influences, but the test of obscenity must agree with the freedom of speech and expression guaranteed under our Constitution. Therefore, sex and nudity in art and literature cannot be regarded as evidence of obscenity without something more

(https://indiankanoon.org/doc/661129/).

The Court went on to admit that obscenity has been understood in the following terms:

(1) That which depraves and corrupts those whose minds are open to such immoral influences.

(2) That which suggests thoughts of a most impure and libidinous character.

(3) That which is hard-core pornography.

(4) That which has a substantial tendency to corrupt by arousing lustful desires [5]. That which tends to arouse sexually impure thoughts.

(6) That which passes the permissive limits judged of from our community standards.

In this case the Hicklin test was applied and given due regard by the court to judge obscenity. After this case Hicklin test was continuously liberalized and applied until the recent case of Aveek Sarkar.

In another such case, $\boldsymbol{K A}$ Abbas $\boldsymbol{v}$. Union of India and Anr (https://indiankanoon.org/doc/1719619/), the Hon'ble Supreme Court validated the pre-censorship of content as exception to the right to freedom of speech and expression. However, the court observed that "the censors need to take into account the value of art while making their decision. The artistic appeal or presentation of an episode robs it of its vulgarity and harm and also what may be socially good and useful and what may not."

While determining that whether a thing presented in a film is obscene or not it should be considered with the context in which that thing is being portrayed and it should not be isolated from the context. Based on this same concept as mentioned, the Supreme Court in case of Bobby Art International \& Ors. v. Ompal Singh Hoon while dealing with the question of obscenity in the context of film called Bandit Queen, ruled that the scenes depicting must not be scene in isolation. Hon'ble court said that the so called objectionable scenes in the film have to be considered in the context of the whole film and with the context that film is seeking to transmit in respect of society. 
Further, In Chandrakant Kayandas Kakodar vs The State of Maharashtra, the Supreme Court observed that the standards of contemporary society in India are fast changing. The adults and adolescents now have available to them a large number of classics, novels, stories and pieces of literature which have a content of sex, love and romance. In the field of art and cinema also the adolescent is shown situations which even a quarter of century ago would be considered derogatory to public morality, but having regard to changed conditions, are more taken for granted without in any way tending to debase or debauch the mind.

In case of Director General, Directorate General of Doordarshan \& Others v. Anand Patwardhan and Another (https://indiankanoon.org/doc/1487930/) in this case an independent filmmaker challenged doordarshan's refusal to telecast his documentary, giving reason that it contain scenes that could promote violence and it's telecast would be against the policies of doordarshan. The court held that tough, there are some scene of violence and social injustices in the film but because of this it cannot be said that the filmmaker supports any of that, and this depiction is only meant to convey that such social evils still exist. The Court also held that a documentary couldn't be denied exhibition on Doordarshan simply on account of its "A" or "UA" certification. The Court held that a film must be judged from an average, healthy and common sense point of view.

In case of Maqbool Fida Husain vs Raj Kumar Pandey Delhi High Court while dealing with the issue of whether a nude painting depicting (Bharat Mata) can be said to be obscene or not. The court answered this in negative and went on observing that «nudity or sex alone cannot be said to be obscene.»

High Court of Bombay in case of state of Maharashtra $v$. Joyce Zee alia Temiko observed that, A customer, above the age of eighteen, who goes to a hotel, where a cabaret show is run, looks forward to be entertained by obscenity and cannot complain of annoyance to which, if any, he shall be deemed to have given his consent.

In the recent land mark judgment of Aveek Sarkar v. State of West Bengal, Hon'ble Supreme Court while dealing with the issue of obscenity finally disapproved the Hicklin's test and adopted the Roth test. The issue was revolving around a picture which was alleged to be obscene in nature. Hon'ble Supreme Court in this case held that "the question of obscenity must be seen in the context in which the photograph appears and the message it wants to convey." The Court further said that the correct test to determine obscenity would be, Community Standards Test i.e. Roth test and not Hicklin Test. The Court observed that in every case related to check on obscenity the material in question to be 'taken as a whole'. When the matter taken as a whole and it is lascivious and tends to deprave the person who reads, see or hear that material, then only that material can be said to be obscene. The court observed that the Hicklin test is in contravention of IPC. Further court observed that as the terms 'obscene' and 'obscenity' is not defined in Indian Law, this makes the community standard test to be more suitable for Indian Law Regime, also, the community standards test is more adaptive to any changing society.

\section{What Next, What should be done?}

\section{Forum and Movement against Obscenity}

At the contemporary time the worst of all pollution is Mind Pollution. It corrupts the most valuable trait of human species: It corrupts THINKING. One of the most common forms of Mind Pollution observed today is obscenity. Therefore, there must have a FORUM against obscenity.

In last few years, a large Section of the Media and particularly the leading ones have taken liberty to flout all norms related to obscenity. A systemic overdose of nudity and vulgarity is being forced into the brain of common viewer through newspapers, television, films, magazines, hoardings, and posters. Their purpose is to use a cheap short cut to catch attention. They want to make quick money by selling their real matter mixed with so called HOT STUFF. The long term effect of this offensive of sex and nudity is resulting in corrupting the thought process because thoughts are bound to come according to what you see, read and hear. The psychologists all over the world are warning that exposure to media violence and sex, have damaging impact on the children, minors and youth. Common man and parents of young children are concerned, they feel helpless and unsatisfied. Their right of bringing up their children in a mind pollution free atmosphere is speedy away. This Long lasting harm cannot be checked individually. It needs a mass movement. This restlessness has evolved into a large number of NGOs and individuals coming together in the form of this 'forum against obscenity'. There is a direct link between the violence being shown in media and the actual act of violence against women. The cases of molestation, sexual harassment and rape are on the rise due to this constant bombardment of sex, nudity and violence in the media, say for example of the incidence in UP, Delhi or in Jharkhand recently.

\section{Future Threat of Obscenity and Need of the Hour}

Marriage as an institution is under threat and danger. Like in West, the cases of divorce are increasing day by day. The Indian culture of a lifelong promise of faithful marital life is likely to get worn. The Foundation of family is being blasted. Sex, instead of a serving a valuable purpose of maintaining intimacy and bond of love between husband and wife, may 
get reduced to a sheer animal act. Teenagers and minors are indulging in sexual activities due to constant striking of adult content in all the media. The body of a woman has become an object of entertainment and a mere commodity to draw people's attention. Therefore the future of obscenity will be more vigorous if it is not stopped now.

The need of the hour is to generate a climate for public dialogue and discussion in the wake of the open sky policy and to make recommendations for public policy. A mechanism should be developed to ensure viewer's feedback, not only on performance but also on expectations, reservations and objections of it. The media should therefore, assume equal responsibilities with parents in creating circumstances and viable conditions that enable projection of women in a decent, dignified way and promote violence free programmes. Television, because of its popularity and mass appeal can be effectively utilized for circulating information, creating awareness and highlighting relevant gender issues for men and women rather than reinforcing gender stereotypes. Being a powerful medium television and social media in general, may be used for provoking thoughts on sensitive issues like sexual harassment, violence against women, denial of opportunities to girl children, reducing manliness among males by showing the relationship between aggressive behaviour and risk taking behaviour among men. Consumerism and the consequent vulgarization of the fabric of our culture are bound to grow unless serious effort is made to control the menace. It is essential to conscript the support of policy makers, parliamentarians, and law makers on the appropriate policy and guidelines for the media to ensure that there is no negative depiction of women. Television and social media also can be used as a forum for advocacy, challenging stereotypes, information distribution that will enable in taking necessary legal action, enactment of appropriate laws, sensitizing the authorities and creating public dialogue. A multi-pronged strategy for sensitization, creating awareness and mobilization of public opinion is needed for developing a positive image of women in media. It is also necessary to draw a fine line between what establishes morality and the define boundaries of obscenity.

\section{References}

1. Anand M (2006) Commodification of Women: The Irony. 'Women's Watch' 3(3).

2. Bathla S (1998) Women, Democracy and the Media. Sage Publications.

3. Joseph A, Sharma K (2006) Whose News: The Media \& Women's Issues. Sage Publications.

4. Nigam S (2002) Women, Obscenity and the law. Legal News and Views 16(12).

5. Nuzhat PK (2006) Cyber Crime and the adequacy of existing Law. Cri DJ Journal 84.

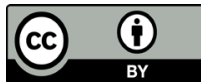

